\title{
A PRÁTICA DE GRUPOS BALINT E A PERCEPÇÃO DO PACIENTE INTERNADO EM HOSPITAL GERAL
}

\section{THE PRACTICE OF BALINT GROUPS AND THE PERCEPTION OF THE INPATIENTS IN A GENERAL HOSPITAL}

\section{VINICIUS FERNANDES'; REGINA CÉLIA VEIGA DA FONSECA²}

\author{
1-Acadêmico de Medicina da Universidade Estadual de Ponta Grossa (UEPG) (Ponta \\ Grossa, PR, Brasil). \\ 2 -Professor ADJUNTO da Universidade Estadual de Ponta Grossa (UEPG) (Ponta \\ Grossa, PR, Brasil). \\ Autor para correspondência: viniciusfbio@hotmail.com
}

\section{RESUMO:}

As questões emocionais vividas pelos pacientes e as formas para lidar com o tema são alvo de discussões há tempos, tanto no meio acadêmico, quanto no meio profissional e no âmbito da saúde. Michael Balint foi um dos pioneiros na abordagem subjetiva do paciente em relação ao seu adoecimento e, assim, desenvolveu os grupos Balint, que contribuiu para a humanização do cuidado para além das questões biológicas das doenças. Hoje se tem falado muito nesse contexto e o quanto isso influencia no cotidiano dos profissionais de saúde. Conversas e, sobretudo, relações humanizadas com o paciente podem ajudá-lo a enfrentar melhor o adoecimento e, também, melhorar a relação médico-paciente possibilitando ampliar diagnósticos e melhorar terapêuticas. Objetivos: avaliar a percepção do paciente internado em relação ao atendimento recebido com grupos Balint; apontar a mobilização emocional do paciente após seu atendimento com grupos Balint; identificar a contribuição da prática com grupos Balint nas reações do paciente em relação ao seu adoecimento e tratamento. Método: Pesquisa transversal, de métodos mistos, que integra abordagens quantitativas e qualitativas. O estudo contou com a participação de 40 pacientes internados no Hospital Santa Casa de Misericórdia e que foram entrevistados na modalidade de Grupos Balint. Os instrumentos utilizados foram uma entrevista fenomenológica e a um questionário estruturado, aplicados aos pacientes, de forma individual. A análise dos dados qualitativos foi realizada por meio de quadros com o núcleo das respostas transcritos, enquanto os dados quantitativos estão em gráficos e demonstram as respostas em relação às perguntas do questionário. Resultados: as respostas da entrevista fenomenológica variaram de acordo com a vivência e experiência de cada paciente, mas a maioria dos comentários foi de satisfação e de benefício com esse diálogo. O mesmo se constatou para o questionário estruturado onde a positividade mostrou-se presente em todas as perguntas avaliadas. Conclusão: a busca pelo acolhimento e compreensão dos sentimentos envolvidos em cada paciente após a conversa com os grupos Balint nos mostra a dimensão do cuidado, o valor da relação estudante/médicopaciente além do acolhimento que esses indivíduos necessitam, não puramente no âmbito biológico, mas psicossocial, fazendo uso de estratégias que melhorem a empatia, a humanização e o estreitamento dos laços com os internados, seja em consultório particular, clínicas ou hospitais.

Palavras-chave: Grupos Balint. Medicina. Adoecimento. Aspectos emocionais. 


\begin{abstract}
:
Emotional issues experienced by patients and ways to deal with this issue have been the subject of discussions for a long time, both in the academic world and in the professional and health environments. Michael Balint was one of the pioneers in the patient's subjective approach to his illness and thus developed the Balint groups which contributed to the humanization of care beyond the biological issues of diseases. Today, much has been said in this context and how much this influences the daily life of health professionals. Conversations and, above all, humanized relationships with the patient can help you better deal with illness and improve the doctor-patient relationship, making it possible to expand diagnoses and improve therapeutics. Objectives: To evaluate the perception of hospitalized patients regarding the care received with Balint groups; To point out the emotional mobilization of the patient after his / her care with Balint groups; To identify the contribution of the practice with Balint groups in the patient's reactions to their illness and treatment. Method: Cross-sectional research of mixed methods, integrating quantitative and qualitative approaches. The study counted on the participation of 40 patients hospitalized at the Santa Casa de Misericordia Hospital and who were interviewed in the modality of Balint Groups. The instruments used were a phenomenological interview and a structured questionnaire, individually for each patient. The analysis of qualitative data was done through tables with the nucleus of the responses transcribed, while the quantitative data were done in graphs, with the answers to the questions asked. Results: the responses of the phenomenological interview varied according to the experience of each patient, but most of the time the satisfaction and benefit of this dialogue is perceived. The same was observed for the structured questionnaire where positivity was present in all the evaluated questions. Conclusion: the search for the reception and understanding of the feelings involved each patient after the conversation with the Balint groups shows us the dimension of care, the value of the student / doctor-patient relationship beyond the reception that these individuals need, not purely in the biological scope, but psychosocial, making use of strategies that improve empathy, humanization and closer ties with internees, whether in private practice, clinics, or hospitals.
\end{abstract}

Key-words: Balint Groups. Medicine. Illness. Emotional Aspects.

\title{
1. INTRODUÇÃO
}

Michael Balint foi um dos pioneiros a trabalhar com a subjetividade dos profissionais de saúde, desenvolvendo atividades associadas à capacitação psicológica de médicos em Londres em 1940. Lá, coordenava discussões a respeito de questões psicológicas da prática médica (BOTEGA, 1996). Uma de suas máximas diz: "O remédio mais usado em Medicina é o próprio médico, o qual, como os demais medicamentos, precisa ser conhecido em sua posologia, reações colaterais e toxicidade". (MACEDO, 2008).

Um dos objetivos dos grupos Balint, é a discussão de casos para que os profissionais da área da saúde obtenham melhor compreensão dos seus pacientes e ampliem seu poder de diagnóstico e tratamento. Outra concepção dos grupos o classifica como recurso para que esses mesmos profissionais entendam mais as questões emocionais vividas por ambos e como isso afeta no processo saúde-doença desses 
indivíduos. (MISSENARD, citado por CASSORLA, 1994).

As conversas com os pacientes são feitas através de anamneses que tem como origem os termos "ana" = trazer de volta, recordar e "mnese" = memória, visando buscar uma boa relação médico-paciente que tem como um dos seus objetivos a melhor adesão ao tratamento, além de melhor confiabilidade dos dados coletados (SANTOS, 1999). Sendo assim, diferentes modelos são empregados atualmente nas escolas de medicina, no entanto a sua objetividade fez com que o curso de medicina da Escola Superior de Ciências da Saúde em Brasília incluísse em seu roteiro, temas relativos à perspectiva do paciente, como (a) repercussões da doença sobre a vida, família e trabalho; (b) temas semelhantes vivenciadas pelo paciente ou por pessoas próximas; (c) conselhos recebidos para lidar com a doença; (d) medidas tomadas pelo paciente para lidar com a doença; (e) principais preocupações atuais; (f) a que atribui a doença (causas); (g) sentimentos relacionados à doença; (h) percepções sobre o tratamento: dificuldades e benefícios; (i) percepções sobre o médico, a equipe de saúde e o atendimento; (j) dúvidas ou assuntos que o paciente julgasse relevantes. (BALDUINO, 2012).

Alguns elementos são considerados importantes para a formação médica e melhor vínculo com o paciente, dentre eles podemos citar a empatia que é alvo de estudos sobre educação e cuidados médicos. O termo citado aumenta a satisfação e a confiança estabelecida pelo paciente (DAVIS, 1983). Esses novos temas abordados diante do paciente buscando compreender sua totalidade, norteiam questões referentes a uma nova (ou velha) perspectiva de humanidade no contexto dialógico médico-paciente, já que a humanização da prática médica tem sido há muito tempo discutida, tanto na imprensa leiga quanto na literatura especializada (JEAMMET, et al. 2000). O foco da humanização no paciente engloba, primordialmente, uma afetividade no cuidado traduzido em acolhida, na ternura, na sensibilidade, no respeito e, sobretudo, na compreensão do doente e não somente na doença. (BACKES, et al. 2005).

Sendo assim, esta pesquisa teve como objetivos, avaliar a percepção do paciente internado em relação ao atendimento recebido com grupos Balint; apontar a mobilização emocional do paciente após seu atendimento com grupos Balint; e identificar a contribuição da prática com grupos Balint nas reações do paciente em relação ao seu adoecimento e tratamento.

\section{METODOLOGIA}

Trata-se de um estudo transversal, de métodos mistos que integra abordagens 
quantitativas e qualitativas com o propósito de ampliar e aprofundar o entendimento e a corroboração dos dados (CRESWELL, 2015).

A abordagem quantitativa tem por objetivo identificar aspectos específicos nos participantes. Para tanto, observa, descreve, classifica e interpreta os dados, indicando a frequência, relação e associação entre as variáveis (DYNIEWICZ, 2007).

A abordagem qualitativa, fenomenológica, busca chegar à intuição das essências, isto é, ao conteúdo inteligível e ideal dos fenômenos, captado de forma imediata, com os participantes em seus sintomas emocionais. O método fenomenológico consiste em mostrar o que é apresentado e esclarecer este fenômeno, tal como se mostra em si mesmo (HEIDEGGER, 1993).

A opção pelo uso dos métodos quantitativo e qualitativo é intencional e necessária, pressupondo um caráter colaborativo entre os dois critérios de pesquisa, pois "enquanto os métodos quantitativos supõem uma população de objetos de observação comparável entre si, os métodos qualitativos enfatizam as especificidades de um fenômeno em termos de suas origens e de sua razão de ser" (TURATO, 2008, p.145).

A pesquisa foi realizada num hospital geral no município de Ponta Grossa (PR), em uma enfermaria com pacientes provindos do SUS, ao longo de cinco meses. A amostra foi composta por 40 pessoas internadas, sendo 24 homens e 16 mulheres, independentemente do tempo de internação. Os participantes desta pesquisa foram potencialmente elegíveis após terem sido atendidos nas aulas práticas da disciplina Psicologia Médica ministradas na Universidade Estadual de Ponta Grossa (UEPG), na modalidade de Grupos Balint. Assim, a disciplina Psicologia Médica foi a base para a realização desta pesquisa que ocorreu, necessariamente, após o término de cada aula prática.

Para a participação dos pacientes neste estudo, os critérios de inclusão estabelecidos foram: (1) pacientes de ambos os gêneros, masculino e feminino; (2) ter acima de 20 anos de idade; (3) estar internado nas enfermarias do Hospital Santa Casa de Misericórdia; (4) aceitar participar do estudo; e (5) ter sido atendido por acadêmicos do terceiro ano de Medicina, na modalidade de Grupos Balint.

Como critérios de exclusão foram considerados: (1) aqueles que não atenderam aos critérios de inclusão definidos para a participação; (2) qualquer alteração ou intercorrência que impedisse o paciente de participar; (3) ser portador de deficiência mental. 
Os instrumentos utilizados foram (1) uma entrevista fenomenológica realizada nas enfermarias do hospital, composta por três perguntas, com roteiro semiestruturado, para investigar a experiência com Grupos Balint e os sentimentos dos pacientes; e (2) um questionário estruturado com dados sociodemográficos e nove perguntas de avaliação da entrevista de Grupos Balint, em que as respostas poderiam variar entre "Bem pouco $=1(\mathrm{um})$ e Muito $=10(\mathrm{dez})$ ".

A análise qualitativa dos dados foi realizada por meio da Análise de Conteúdo Temático (MINAYO, 2007). A partir da leitura exaustiva e análise das entrevistas, identificaram-se unidades de significado, que foram posteriormente agrupadas em temas relacionados à experiência dos pacientes. Quanto aos dados quantitativos, foram apresentados por meio de análise estatística dos índices encontrados, sob a forma de uma escala de tipo Likert.

O projeto foi submetido e aprovado pelo Comitê de Ética de Pesquisa em Seres Humanos da UEPG, sob o Parecer oㅜ 1.715.804 em 07/09/2016. Foram respeitados os Termos de Consentimento Livre e Esclarecido (TCLE) dos participantes da pesquisa, sendo os convidados informados sobre os objetivos e riscos da pesquisa, bem como do próprio TCLE, no ato do convite e antes do início da coleta de dados. A pesquisa teve autorização prévia das instituições envolvidas.

\section{RESULTADOS E DISCUSSÃO}

\subsection{Resultados qualitativos}

Da amostra de participantes, $100 \%$ eram brasileiros, $90 \%$ dos homens possuíam alguma religião e $95 \%$ das mulheres idem. A respeito da escolaridade, $72 \%$ dos homens e $81 \%$ das mulheres terminaram o ensino médio, o restante não havia terminado o ensino médio. Em relação à idade dos pacientes entrevistados, houve uma variação de 20 até 79 anos para homens e 22 até 76 anos para mulheres.

Os entrevistados estavam internados em uma ala específica, agrupados em quartos, conforme a doença vigente na internação, quais sejam, cardiopatias, doenças renais ou câncer.

Os resultados qualitativos, gerados pela entrevista realizada para cada um dos pacientes, estão expostos a seguir (Quadros 1, 2 e 3), com o núcleo das respostas dos participantes e suas respectivas unidades de significado (sentimentos, diferença e opinião), 
conforme cada pergunta da entrevista fenomenológica.

Quadro 1: Questão1 - Como você se sentiu após a entrevista com os acadêmicos de medicina?

\begin{tabular}{|c|c|}
\hline $\begin{array}{l}\text { Unidades de significado: } \\
\text { SENTIMENTOS }\end{array}$ & $\begin{array}{l}\text { Respostas dos pacientes após a entrevista com os acadêmicos de medicina: } \\
\qquad \text { NÚCLEO DAS RESPOSTAS }(\mathrm{N}=40)\end{array}$ \\
\hline (1) Bem-estar & $\begin{array}{|ll|}\checkmark & \text { Me senti bem (discurso de dois pacientes) } \\
\checkmark & \text { Me senti bem; as perguntas que eles fizeram foram bem orientadas. } \\
\checkmark & \text { Me senti bem; alegre; já estava calmo, mas fiquei melhor ainda depois da conversa. } \\
\checkmark & \text { Já estava tranquilo, mas a troca de ideias e a conversa com alguém me fez sentir } \\
& \text { melhor. } \\
\checkmark & \text { Os alunos foram educados, então me senti bem. } \\
\checkmark & \text { Me senti bem, pois os alunos me passaram a sua alegria. } \\
\checkmark & \text { Me senti melhor porque assim o tempo passa mais depressa. } \\
\checkmark & \text { Me senti bem; tranquilo; fico feliz pelos alunos terem forças para continuar. } \\
\checkmark & \text { Eu estava nervoso, mas fiquei melhor depois de conversar com os alunos. } \\
\checkmark & \text { Me senti melhor, pois pude desabafar com alguém. } \\
\checkmark & \text { As conversas me fizeram bem. }\end{array}$ \\
\hline (2) Acolhimento & $\begin{array}{l}\checkmark \text { Me senti acolhido; me tiraram o nervosismo de estar internado. } \\
\checkmark \text { Coloquei pra fora todos os pensamentos ruins; me senti acolhido pela atenção que } \\
\text { eles me deram. }\end{array}$ \\
\hline (3) Alívio & $\begin{array}{l}\checkmark \text { Senti um alívio, pois diminui a tensão que estava vivendo. } \\
\checkmark \text { Aliviado porque desabafei. } \\
\checkmark \text { Me senti aliviado, pois ficamos preocupados com o internamento. }\end{array}$ \\
\hline (4) Felicidade & $\begin{array}{l}\checkmark \text { Contente e feliz; achei importante, pois serve pra orientar a vida das pessoas; ajudar } \\
\text { alguém de alguma forma. } \\
\checkmark \text { Me senti feliz; acho importante para a formação deles conversar com os pacientes; }\end{array}$ \\
\hline (5) Apoio & $\begin{array}{ll}\checkmark & \text { Me apoiaram. } \\
\checkmark & \text { Eu estava triste, chorando. O apoio deles me ajudou a me sentir melhor. } \\
\checkmark & \text { Me senti apoiado pelos alunos e motivado para seguir em frente. }\end{array}$ \\
\hline (6) Tranquilidade & $\begin{array}{ll}\checkmark & \text { Tranquilidade ao conversar com eles } \\
\checkmark & \text { Tranquilidade; antes da conversa estava nervoso. } \\
\checkmark & \text { Me senti tranquilo; é como conversar com um psicólogo; a gente se abre. } \\
\checkmark & \text { Me senti leve após conversar com os alunos; eles nos deixam mais tranquilos. }\end{array}$ \\
\hline (7) Emoções diversas & \begin{tabular}{|lll}
$\checkmark$ & Estava pensando em bobagens; foi bom ter alguém pra conversar. \\
$\checkmark$ & Ter alguém pra conversar espairece. \\
$\checkmark$ & Foi reconfortante conversar com alguém. \\
$\checkmark$ & Fiquei animado, pois estava sozinho no quarto. \\
$\checkmark$ & Eles são nosso futuro. Fico emocionado em ver como eles são agora pra imaginar
\end{tabular} \\
\hline (8) Indiferença (*) & vo; me senti normal; já gosto de conversar então foi in \\
\hline
\end{tabular}

Perpassando pelas respostas dos pacientes viajamos por um mundo de grandes significados onde o paciente e os estudantes de medicina estão num posto de íntima relação, o que se projeta para as relações que médicos têm para com seus pacientes. É indubitável o que um simples sorriso ou um gesto de carinho pode fazer na vida desses indivíduos, por vezes fragilizados por inúmeros motivos, além da própria internação. 
Uma das principais características de uma boa relação médico-paciente está em ouvi-lo de maneira atenta e cuidadosa. Zimerman (1992) pondera que o profissional de saúde deveria se esforçar para compreender o paciente com a seguinte fala: "não há nada pior no ato médico do que o 'diálogo de surdos' da incomunicação..." com isso, muitas vezes nos deparamos com médicos não aptos a ouvir, ou mesmo, pacientes a ponto de entender as angústias alheias. "Me senti aliviado, pois ficamos preocupados com o internamento". (Unidade de significado 3. Alívio).

O mesmo ocorre com os estudantes de medicina, a atenção dada aos pacientes é enxergada por eles de forma semelhante aos dos profissionais formados. São o espelho de uma sociedade conservadora que espera deles o melhor em sua formação. "O fato deles perguntarem como estou mesmo sem me conhecer foi ótimo". (Unidade de significado 1: Bem-estar).

A boa comunicação entre profissionais de saúde (aqui representados pelos acadêmicos de medicina) e pacientes, oferece melhores condições de relacionamento para ambas as partes e traz à evidência dos olhares atentos, sentimentos gerados a partir de então. Isso transmite para os pacientes uma forma diferente de reconhecimento do profissional por meio do acadêmico no sentido de projetar nele um futuro médico mais compreensível. "Eles são nosso futuro. Fico emocionado em ver como eles são agora pra imaginar o depois". (Unidade de significado 7: Emoções diversas).

Além disso, outro fator importante nesta relação é o acolhimento por parte dos profissionais. Inúmeras vezes essa palavra foi destaque nas entrevistas. Neste sentido percebe-se a importância dada pelos pacientes a esse assunto. Isso levanta a discussão que vem sendo feita no Sistema Único de Saúde, tendo como foco o profissional e o usuário (SUCUPIRA, 2007). No entanto, a franca existência de livros didáticos sobre o tema chama a atenção, por isso esse tema se configura em âmbito marginal devido, principalmente, a uma formação baseada num modelo biológico organicista que predomina no ensino médico. "Me senti acolhido; me tiraram o nervosismo de estar internado"; "Se sensibilizaram com a minha doença, assim me senti mais acolhido"; "Coloquei pra fora todos os pensamentos ruins; me senti acolhido pela atenção que eles me deram". (Unidade de significado 2: Acolhimento).

Ainda, segundo Sucupira (2007), a maior compreensão do paciente nessa relação se dá não apenas pelo domínio de uma técnica, sobretudo estática e engessada, mas implica na necessidade de uma formação mais amplificada e generalizada em que se obtenha subsídios de diversas disciplinas não somente biológicas, mas humanas, a fim de expressar nas condutas e atitudes o que foi aprendido. "Me senti feliz; acho importante para a formação deles conversar com os pacientes; fico bem feliz". (Unidade de significado 4: Felicidade).

Essa relação pode ser considerada uma via de mão dupla. Assim, todos são 
beneficiados, como uma relação simbiótica, o aprendizado se dá para ambas as partes. Neste sentido, Grosseman e Patricio (2004) analisam que para a construção de relações de diálogo, além de uma relação interpessoal entre ambas as partes, há necessidade de valorizar o outro em sua identidade, respeitando suas experiências e essencialmente a sua própria existência como ser único e insubstituível. "Contente e feliz; achei importante, pois serve pra orientar a vida das pessoas; ajudar alguém de alguma forma”. (Unidade de significado 4: Felicidade).

Para Videla (1998), a solidariedade é um ponto forte nessa relação de simbiose; os pacientes têm fome de solidariedade, isso porque a doença humilha, corrói o sentido do "eu" o que os torna sensíveis à palavra do profissional de saúde e é nesse ponto a chave para concretizar uma melhor relação das partes envolvidas, onde deve-se cultivar a flexibilidade e a tolerância preservando também o ponto de vista dos pacientes. "Me senti tranquilo; é como conversar com um psicólogo; a gente se abre". (Unidade de significado 6: Tranquilidade).

Diante da relação médico-paciente, nos deparamos com uma formação em que o subjetivo dos pacientes deve ser estimulado, na busca pelo cuidado e pela atenção que é dada a eles, a fim de que a interação das partes seja beneficamente mutualística. Balint (1988) acreditava que em sua formação acadêmica os estudantes eram "catequizados" a fazer com que o paciente seguisse ordens, isso porque o médico seria o detentor pleno do saber, portanto toda a fé deveria ser depositada nele sem questionamentos; entretanto a doença não deve ser entendida como um fenômeno isolado, mas relacionando o indivíduo ao seu contexto ambiental.

Como a pesquisa envolve indivíduos em diferentes contextos pessoais, apesar de internadas numa mesma ala de enfermaria, cada indivíduo é único e por isso nem todos analisam as visitas dos grupos Balint de forma positiva como vemos na fala do paciente que demonstrou nitidamente indiferença à visita dos alunos. O grau de importância que cada um confere, depende do seu contexto social e também da empatia demonstrada durante a entrevista. "Não foi muito significativo; me senti normal; já gosto de conversar então foi indiferente". (Unidade de significado 8: Indiferença).

A construção da relação médico-paciente (estudante-paciente) deve, também, pautar-se em subjetividade. Isso se torna fundamental para definir e projetar a real qualidade da prática médica. Com isso, Balint (1988) afirma que "o remédio mais usado em medicina é o próprio médico o qual, como os demais medicamentos, precisa ser conhecido em sua posologia, reações colaterais e toxicidade".

Com isso a subjetividade demonstrada a partir dos sentimentos e emoções vividas pelos pacientes, após entrevistas com os alunos que compõem os Grupos Balint da Universidade Estadual de Ponta Grossa, expõem a importância dessa relação. O cuidado 
com as palavras usadas nos diálogos nos mostra a individualidade e a complexidade de cada paciente; como eles sentem falta de um atendimento que se considere todo o seu "eu" e não somente o ser orgânico que ele também é.

Quadro 2: Questão 2 - A vinda dos acadêmicos e a entrevista com eles fez diferença em sua vida e/ou na sua internação? Por quê?

\begin{tabular}{|c|c|}
\hline $\begin{array}{l}\text { Unidades de } \\
\text { significado: OPINIÃO }\end{array}$ & $\begin{array}{l}\text { Resposta dos pacientes sobre a entrevista com os acadêmicos de medicina: } \\
\text { NÚCLEO AS RESPOSTAS }(\mathrm{N}=10)\end{array}$ \\
\hline Positiva & $\begin{array}{ll}\checkmark & \text { Fez com que eu parasse de pensar na doença. } \\
\checkmark & \text { Eles me falaram palavras boas e de conforto. } \\
\checkmark & \text { Consegui mais confiança para lutar e permanecer firme na luta. } \\
\checkmark & \text { O dia que sair daqui lembrarei que os alunos estiveram aqui para me ajudar. } \\
\checkmark & \text { Sinto agora mais força para viver mais e melhor. } \\
\checkmark & \text { Lembro de Deus nesses momentos, pois foi Ele que os trouxe aqui. } \\
\checkmark & \text { Sou uma pessoa muito sozinha, então, quando aparece alguém pra conversar fico } \\
\text { radiante. } \\
\checkmark & \text { As conversas me distraíram do internamento. } \\
\checkmark & \text { Fiquei melhor do que estava; gosto de conversar. } \\
\checkmark & \text { É bom conversar abertamente sobre tudo. } \\
\checkmark & \text { Me senti apoiada, pois estava ansiosa para ir embora. } \\
\checkmark & \text { Pela vontade deles de ajudar alguém me senti honrado. } \\
\checkmark & \text { Mesmo internada posso servir para alguma coisa (de estudo). } \\
\checkmark & \text { Se dermos uma boa palavra para os alunos, eles se sentirão bem e } \\
& \text { consequentemente ajudarão melhor os outros. } \\
\checkmark & \text { Os ensinamentos deixados por eles são únicos. } \\
\checkmark & \text { Tive a oportunidade de aconselha-los a não beber, fumar ou parar os estudos. } \\
\checkmark & \text { As conversas me distraíram. } \\
\checkmark & \text { Melhoramos como pessoas após conversas desse tipo; guardamos o que é bom do } \\
& \text { outro. } \\
\checkmark & \text { Melhorei como pessoa. } \\
\checkmark & \text { Me ajudaram a passar melhor o tempo. } \\
\checkmark & \text { Melhoraram meu bem-estar aqui dentro do hospital. } \\
\checkmark & \text { Conversas 'assuntadas' nos ajudam a compreender melhor a vida. } \\
\checkmark & \text { Conhecer novas pessoas me ajuda a fazer novos amigos. } \\
\checkmark & \text { Fiquei mais contente depois da visita deles. } \\
\checkmark & \text { Ajuda a passar o tempo. } \\
\checkmark & \text { Me deixaram mais motivado a seguir em frente e pensar na minha família. } \\
\checkmark & \text { Um estímulo para seguir em frente para que minha vida e da deles melhore. } \\
\checkmark & \text { Acho importante para o desempenho profissional. } \\
\checkmark & \text { O apoio que senti me dá força para seguir. } \\
\checkmark & \text { Parece que nasci de novo após conversar com eles. } \\
\checkmark & \text { Me transmitiram força e conhecimento. } \\
\checkmark & \text { Sinal de interesse por eles sobre minha doença. } \\
\checkmark & \text { O médico nos devolve a vida. } \\
\checkmark & \text { A gente fica mais animado e esquece da doença. } \\
\checkmark & \text { Hoje é para mim, amanhã é para outro que eles dão apoio }\end{array}$ \\
\hline Neutra & $\begin{array}{ll}\checkmark & \text { Fez diferença, mas principalmente para eles. } \\
\checkmark & \text { É diferente se abrir para desconhecidos. }\end{array}$ \\
\hline Indiferente & $\begin{array}{l}\checkmark \text { Pra mim foi normal; não fez diferença a vinda deles, pois sou bem resolvido comigo } \\
\text { mesmo. } \\
\text { Não fez diferença porque já estava tranquilo, então, a vinda deles também foi } \\
\text { tranquila pra mim. }\end{array}$ \\
\hline (4) Preocupação & mım eram in \\
\hline
\end{tabular}

Fonte: Dados da pesquisa (2016) 
Vemos que a maioria dos pacientes submetidos à entrevista fenomenológica avaliam de forma positiva as conversas tidas com os alunos. Por vezes, eles se mostram sensíveis às questões devido aos seus contextos e a subjetividade que cada um traz consigo. Em diferentes falas percebemos que a positividade e o bem-estar prevalecem diante dessa comunicação e isso vem ao encontro da primeira questão abordada anteriormente neste artigo, corroborando para a avaliação deste trabalho.

A partir do entendimento da interação do paciente com o seu internamento, podemos analisar fatores de risco e de proteção envolvidos no processo saúde-doença daquele indivíduo. Sendo assim, a positividade diante da situação em que se encontra, ao receber os alunos, torna-se mais agradável e mostra certa resiliência por parte deles como variável de proteção à saúde. Segundo Morais e Koller (2004), a construção de aspectos positivos que incluem resiliência, bem-estar, otimismo, felicidade, esperança, dentre outros, é algo que deve ser trabalhado e melhorado para uma melhor relação de confiança que deve ser estabelecida com o outro. "Melhoraram meu bem-estar aqui dentro do hospital". (Unidade de significado 1: Positiva).

As percepções de melhora no internamento após o diálogo com os estudantes são notáveis pela alegria nas falas dos internados, trazendo grandes benefícios para cada um deles. É o que comprova um ramo da ciência denominado neuropsicoimunologia que estuda a associação entre o sistema nervoso, imune e endócrino; neurotransmissores e citocinas desempenhariam relativo papel no processo saúde-doença. Com isso, Berk (2001), Martin (2001) e Mahony (2002) demonstraram os benefícios do riso enquanto ator importante nessas situações de fragilidade para o sistema imune, elevando a atividade de células de defesa e diminuição na produção de hormônio do estresse.

O estado emocional é um grande influenciador na internação desses pacientes. A esperança de terem alta hospitalar o quanto antes é uma constante e ter alguém que confronte qual será o próximo passo a seguir em suas vidas é algo que os pacientes não estão acostumados a fazer. Por vezes eles se encontram carentes diante da situação em que se encontram; fragilizados por inúmeros motivos inerentes a esse processo. A reciprocidade de sentimentos envolvidos nas entrevistas relatada pelos pacientes mostra a importância e a repercussão dessa positividade. Para Danner (2001) existe uma associação entre o estado emocional e longevidade, sendo que palavras relacionadas a emoções positivas como amor, alegria, felicidade proporcionam anos extras de vida se comparados 
às pessoas negativas, além de menor grau de demência senil. "A gente fica mais animado e esquece da doença". (Unidade de significado 1: Positiva).

Além disso, a espiritualidade e a religiosidade estiveram incluídas na positividade e se fizeram presentes nas entrevistas, visto que a grande maioria dos pacientes possuíam algum tipo de religião. Nesse aspecto, a religião pode ser considerada uma dimensão da natureza humana associada à qualidade de vida já que muitas vezes norteia e dá suporte a processos de adoecimento. A relação que esse indivíduo tem sobre seu bem-estar pode levá-lo a valorizar e entender seu sentido da vida. Quando elevamos essas crenças no contexto prático, as influências dos aspectos religiosos no enfrentamento das adversidades são intrigantes e merecem a devida atenção, já que o paciente não deve ser visto somente como um ser biológico, mas também psicossocial (CALVETTI, et al, 2007). "Lembro de Deus nesses momentos, pois foi Ele que os trouxe aqui" (Unidade de significado 1: Positiva).

Observou-se, ainda, aqueles pacientes que se mostraram neutros ou indiferentes às perguntas da entrevista fenomenológica. É possível que isso aconteça em decorrência a diversos fatores, dentre eles a fase de negação que podem estar inseridos em relação ao diagnóstico por eles recebidos; desconforto pela situação em que se encontram, fragilizados por um internamento que por muitas vezes é doloroso e sacrificante. Ou simplesmente por não estarem acostumados com esse tipo de conversa mais subjetiva, em que seus sentimentos são abordados de forma explícita não demonstrando assim, o que realmente sentiram.

Em consonância, notou-se, também, um paciente que se mostrou preocupado com esse tipo de diálogo. Vale aqui ressaltar sua origem: era um paciente morador de zona rural, tímido e retraído. Para ele, esse tipo de conversa extrapolava o que seu imaginário e vivência do que é ser médico e o que é ser paciente, sob um contexto onde o primeiro somente faz perguntas objetivas em relação à sua doença e o segundo acata sem pestanejar as decisões advindas do "detentor do saber científico". Para o profissional é importante notar tal constrangimento, pois diante de situações como essa a abordagem pode ser outra, no sentido de dar mais espaço ao paciente e assim estabelecer a melhor relação possível dentro das crenças do internado. 
Quadro 3: Questão 3 - O que você pensa ou acha sobre a entrevista em que você falou com os acadêmicos sobre seus sentimentos em relação à sua doença e à sua vida com a doença?

\begin{tabular}{|c|c|}
\hline $\begin{array}{l}\text { Unidades de significado: } \\
\text { OPINIÃO }\end{array}$ & $\begin{array}{l}\text { Resposta dos pacientes sobre a entrevista com os acadêmicos de medicina: } \\
\text { NÚCLEO DAS RESPOSTAS ( } \mathrm{N}=10)\end{array}$ \\
\hline (5) Positiva & $\begin{array}{l}\checkmark \text { As conversas nos fazem esquecer da doença e foca em outras coisas. } \\
\checkmark \text { A partilha é boa para descarregar sentimentos negativos e demônios. } \\
\checkmark \text { Essas conversas às vezes ajudam mais do que os medicamentos convencionais. } \\
\checkmark \text { Achei maravilhoso, pois me senti bem melhor depois de me abrir } \\
\text { sentimentalmente. } \\
\checkmark \text { Legal, pois tira a cabeça dos problemas. } \\
\checkmark \text { Seria bom se os médicos perguntassem sobre nossos sentimentos. } \\
\checkmark \text { Acho importante devido ao nosso sofrimento aqui dentro. } \\
\checkmark \text { Importante, pois ficamos tristes e preocupados com a cirurgia e a recuperação. } \\
\checkmark \text { Por ser jovem, me senti mais a vontade de conversar com eles. } \\
\checkmark \text { Pude desabafar e me sentir melhor. } \\
\checkmark \text { É importante que os alunos aprendam maneiras diferentes de conversar com os } \\
\text { pacientes pra que o acolhimento seja melhor. } \\
\checkmark \text { A importância sobre essas conversas é imensurável; não consigo definir com } \\
\checkmark \text { palavras. } \\
\checkmark \text { Acho bom, pois podemos trocar conhecimentos. } \\
\checkmark \text { foi animador. Esse tipo de conversa pode "ajudar outras pessoas". } \\
\checkmark \text { Bom, pois incentiva as pessoas a melhorarem. } \\
\checkmark \text { É bom, pois tiramos nossas dúvidas. } \\
\checkmark \text { Acho importante. } \\
\checkmark \text { Bom, porque é bom conversar. } \\
\checkmark \text { Bom, pois eles cuidam da gente de outras formas. } \\
\checkmark \text { Conversar sobre meus sentimentos } \\
\checkmark \text { O diálogo me ajudou a me abrir melhor. } \\
\checkmark \text { Pra mim foi um desabafo; alívio de problemas; sinto felicidade em me abrir. } \\
\checkmark \text { Acho positivo alguém me perguntando sobre esse assunto; me deixaram com a estima } \\
\checkmark \text { élevada. } \\
\checkmark \text { É importante cuidar da alma, não só do corpo; fortalece o espírito. } \\
\checkmark \text { Esse tipo de conversa nos ajuda a animar mais para seguir em frente. }\end{array}$ \\
\hline (6) Educaçã & $\begin{array}{l}\checkmark \text { Essa abordagem faz os estudantes aprenderem mais. } \\
\checkmark \text { Acho que os alunos aprendem mais e isso dá nota pra eles na faculdade. } \\
\checkmark \text { Assim percebo o valor do aprendizado. } \\
\checkmark \text { Como eles estão estudando para serem médicos é importante escutarem esse lado. } \\
\checkmark \text { Assim há uma interação maior com os problemas alheios; aprendem a se importar } \\
\text { melhor com os outros. } \\
\checkmark \text { Incentiva o aprendizado deles. }\end{array}$ \\
\hline (7) Neutra & $\begin{array}{l}\checkmark \text { As conversas com os alunos são diferentes. } \\
\checkmark \text { É uma nova experiência. } \\
\checkmark \text { Acho que é importante para eles; a diferença foi feita na vida deles e não na minha. } \\
\checkmark \text { É difícil responder; falta tempo para os médicos falarem sobre esses assuntos } \\
\text { conosco. }\end{array}$ \\
\hline (8) Negativa & $\begin{array}{l}\checkmark \text { Não acho importante; prefiro que os alunos não perguntem sobre minha vida } \\
\text { pessoal; seria melhor se eles só falassem sobre o problema da internação; talvez por } \\
\text { ser da área rural não me senti confortável. }\end{array}$ \\
\hline (9) Desconforto & $\begin{array}{l}\checkmark \text { Para mim é difícil falar sobre meus sentimentos; perdi um filho e por isso evito } \\
\text { o assunto. }\end{array}$ \\
\hline
\end{tabular}

Fonte: Dados da pesquisa (2016) 
Aqui o destaque vai para a percepção dos pacientes sobre esse modo de dialogar, onde os seus sentimentos eram colocados à prova. Assim como nas perguntas anteriores da entrevista fenomenológica, esta foi de grande valia, pois vemos o quão sólido e positivo é para a grande maioria dos internados falar sobre sua subjetividade em relação ao adoecimento, e não somente o biológico em seu tecnicismo que, por detrás dos estudantes, se projetam como uma figura do profissional médico, diante dos pacientes.

Diante das falas demonstradas no quadro 3 , nos salta aos olhos uma das palavraschave para questão-problema: humanização.

O tema humanização é algo que se discute atualmente diante da necessidade de se humanizar o serviço, seja pelo cuidado, assistência ou relação com o paciente. Sendo assim, o sistema único de saúde implementou uma política de atenção à saúde que englobasse tal tema; apesar disso, ainda encontramos fragmentações e baixo investimento dos diversos serviços prestados, o que impede que essa proposta seja ampliada e concretizada adequadamente. (OLIVEIRA et al, 2006).

Oliveira et al (2006) também destacam que a garantia da humanidade é dar à palavra a sua dignidade ética, sobretudo em relação ao sofrimento humano e as percepções de dor que precisam da compreensão das palavras ditas pelo outro e a compreensão das mesmas. Mas não somente; a linguagem não verbal pode e deve contribuir para esse processo no sentido de acolher e prestar cuidado a esses pacientes. Por esse e por outros motivos, humanizar não é só "amenizar" o internamento hospitalar, mas ir em oposição à inumanidade, independente da forma com que ela se apresente. "Acho importante devido ao nosso sofrimento aqui dentro"; "É importante que os alunos aprendam maneiras diferentes de conversar com os pacientes pra que o acolhimento seja melhor". (Unidade de significado 1: Positiva).

Ir além das aparências é o que o profissional de saúde (incluindo os acadêmicos) deve fazer segundo Bettinelli et al (2003), valorizando aspectos relativos aos fenômenos da vida humana que os pacientes demonstram. Com isso a capacidade de compreender o ser humano e como ele constrói sua história de vida deve ser valorizada no momento da entrevista.

A demonstração de sentimentos envolvidos nas conversas demonstra um outro lado do paciente. Lado esse, pouco ou quase nunca valorizado pelo profissional de saúde ou acadêmico. Erro crasso quando se pensa no indivíduo como um ser fragmentado e não em sua totalidade. A exposição desses sentimentos algumas vezes projeta a atenção que se deveria fornecer a quem o transfere. "Assim há uma interação maior com os problemas alheios; aprendem a se importar melhor com os outros". (Unidade de significado 2: Educação médica).

O entendimento por parte dos usuários sobre o porquê da falta de atenção ou humanidade por parte dos profissionais é diverso. O que se percebe é a frustração por parte dos pacientes em querer ser cuidado de forma integral, com maior atenção e de maneira a 
se sentirem acolhidos ou apoiados pelos médicos e a equipe. "É difícil responder; falta tempo para os médicos falarem sobre esses assuntos conosco". (Unidade de significado 3: Neutra).

Em relação aos acadêmicos, os pacientes sentiram-se acolhidos pelo atendimento. $\mathrm{O}$ fato de serem estudantes e futuros profissionais projetou expectativas por parte dos indivíduos internados; uma esperança de que serão médicos melhores; que não se importarão somente com o tecnicismo, mas com a vida em sua forma ampla mesclando biológico e psicológico. A provocação aos sentimentos trouxe à tona uma variedade de demonstrações que são percebidos em suas falas. "Acho positivo alguém me perguntando sobre esse assunto; me deixaram com a estima elevada". (Unidade de significado 1: Positiva); "Como eles estão estudando para serem médicos é importante escutarem esse lado". (Unidade de significado 2: Educação médica).

Entendendo a vida e o contexto pessoal de cada um, é de se esperar que nem todos gostem de demonstrar seus sentimentos, porque em seu entendimento pode ser uma demonstração de fragilidade. No entanto é unânime a premissa de que os acadêmicos deveriam se preocupar em entender o paciente em seu contexto social com angústias e preocupações por inúmeros motivos e assim tentar ajudá-lo de maneira sutil e eficiente, mesmo que apenas escutando-o. "Não acho importante; prefiro que os alunos não perguntem sobre minha vida pessoal; seria melhor se eles só falassem sobre o problema da internação; talvez por ser da área rural não me senti confortável". (Unidade de significado 4: Negativa); "Acho que é importante para eles; a diferença foi feita na vida deles e não na minha". (Unidade de significado 3: Neutra).

Backes et al (2005) já afirmava que para os pacientes a humanização se traduzia em gestos concretos como sentimento de solidariedade, sensibilidade e compaixão. Não se limitando, portanto, a uma relação paciente-profissional ou vice e versa, mas teria um sentido mais amplo e plural. Dito isso, a humanização vai além de uma forma de ser no espaço institucional, onde o foco se concentra no doente e na doença, significa ir além da patologia vigente. $O$ desabafo dito pelos entrevistados mostra esse significado; 0 de entender como o outro se sente ou pelo menos se preocupar como ele vive. "Pra mim foi um desabafo; alívio de problemas; sinto felicidade em me abrir; "Pude desabafar e me sentir melhor". (Unidade de significado 1: Positiva).

Além disso, as respostas à pergunta do quadro 3 , mostram na sua maioria, a importância de dois principais aspectos: o benefício do cuidado humano e psicológico ao paciente internado, que se sente acolhido pelo profissional da saúde; e a importância de adicionar esse hábito à prática médica, tanto no âmbito hospitalar, quanto em clínicas e consultórios, visto que a dinâmica da anamnese pode ser ajustada para que ambos, paciente e profissional, possam ganhar em termos de adesão ao tratamento, acolhimento, compreensão e sensibilidade ao diagnóstico. 


\subsection{Resultados quantitativos}

Com relação aos resultados quantitativos da pesquisa, encontram-se expostos a seguir, nos gráficos de um a nove, que apresentam as perguntas com o número de participantes distribuídos, conforme as respostas ao questionário aplicado.

Para a discussão das respostas, estabeleceu-se sua divisão em dois grupos: as notas de 1 a cinco (1-5), receberam conceito negativo e as notas de seis a dez (6-10), recebem o conceito positivo. Exceto a pergunta de número 4 (Gráfico 4) em que essas relações foram invertidas devido ao conteúdo da questão.

Gráfico 1. Você se sentiu à vontade quando os alunos de Medicina estiveram aqui para conversar e perguntar sobre a sua doença?

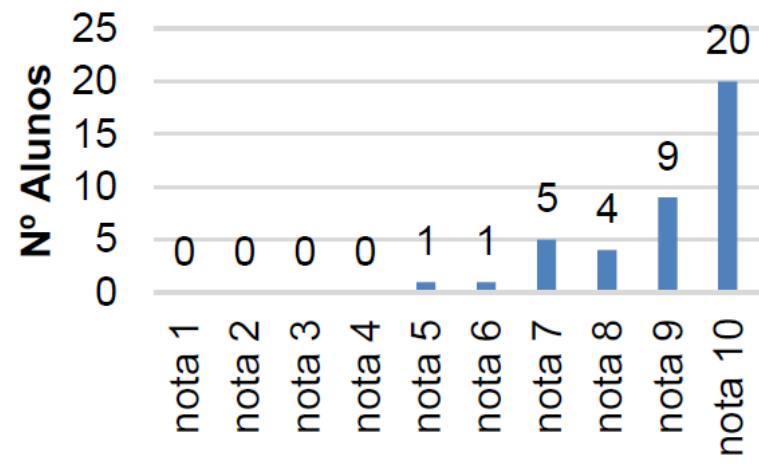

Avaliação

Gráfico 2. As questões relativas à sua doença lhe aproximaram do aluno?

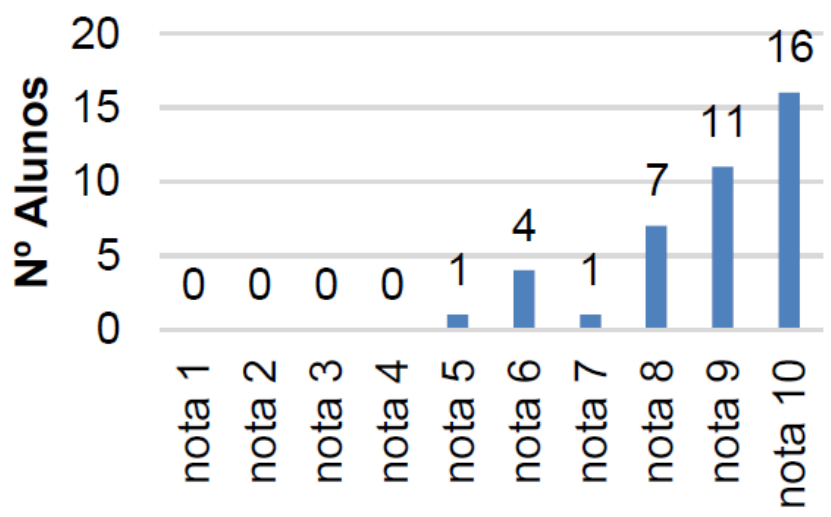

Avaliação

Dos 40 participantes que responderam ao questionário desta pesquisa, 39 (97,5\% - Gráfico 1) ficaram à vontade ao serem questionados sobre os motivos do seu internamento e suas angústias devido ao seu quadro, sobretudo em relação a aproximação 
que eles referiram sentir, avaliados pelo gráfico 2 onde é perceptível isso, visto que o índice de positividade também foi de $97,5 \%$.

Gráfico 3. Falar sobre a sua doença ajudou você a se sentir melhor?

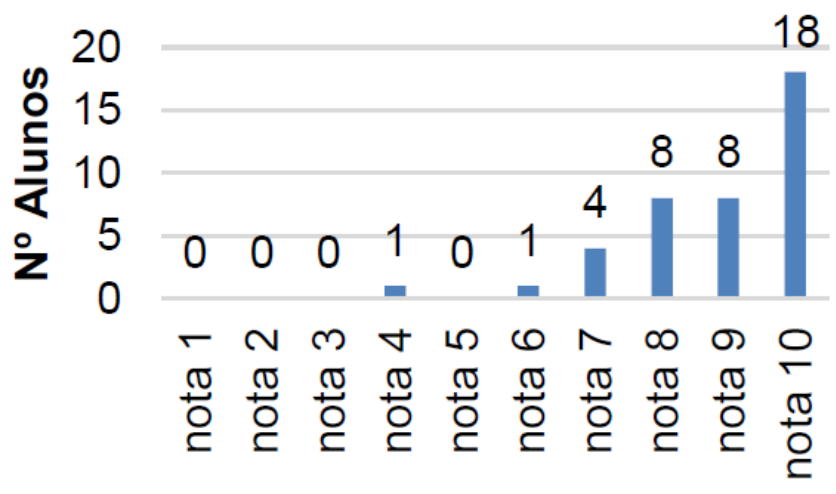

Avaliação

Gráfico 4. Ao falar para o estudante sobre suas emoções diante da doença, você se sentiu constrangido (com vergonha)?

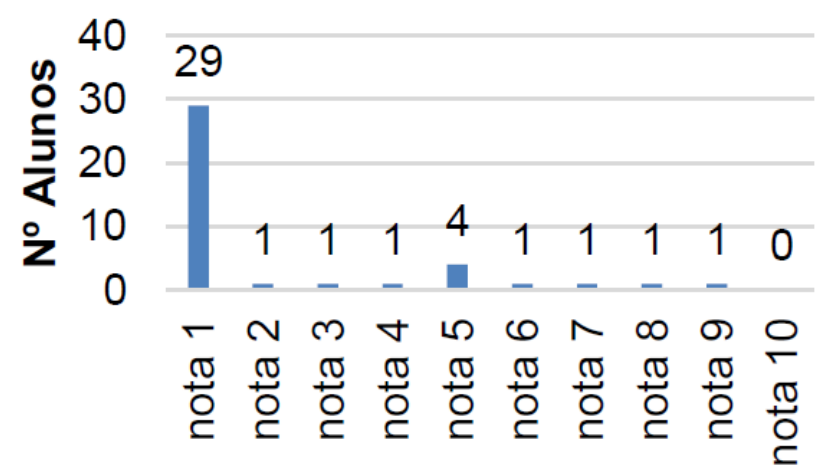

Avaliação

Ao serem questionados sobre sua doença e a possibilidade de falar abertamente sobre 0 assunto, sem pudores ou ressalvas, percebemos que a ampla maioria se sente melhor ao expor-se (97,5\% dos entrevistados - Gráfico 3). Isso corrobora para a quarta pergunta (Gráfico 4), onde o constrangimento foi abordado, de forma que ali o paciente pudesse demonstrar o quanto ficou envergonhado ou receoso de falar algo e ser julgado ou ficar numa situação de embaraço; sendo assim, poucos (oito) pacientes ficaram com vergonha ou constrangidos, de alguma forma, e isso foi perceptível principalmente em pacientes vindo de zonas rurais, cujos relatos percebe-se uma forma mais retraída de lidar 
com a diálogo humano.

Gráfico 5. Ao fazer essa entrevista, você sentiu-se apoiado (ou acolhido) pelo aluno de Medicina?

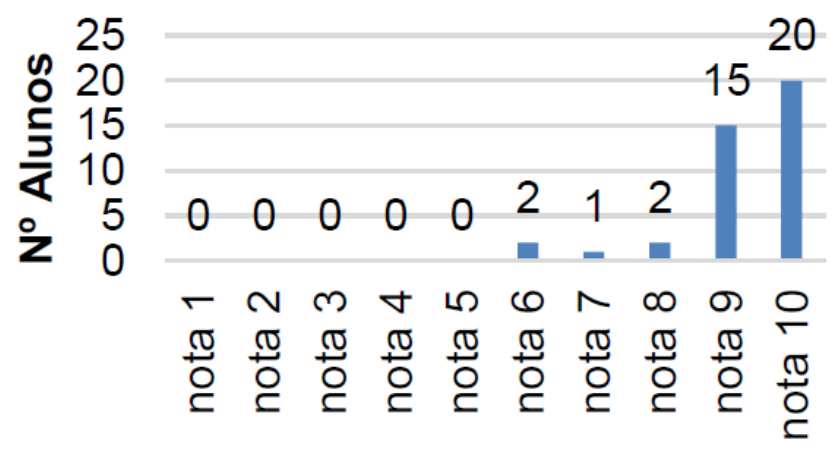

Avaliação

Gráfico 6. Você se sentiu à vontade quando os alunos de Medicina estiveram aqui para conversar e perguntar sobre a sua doença?

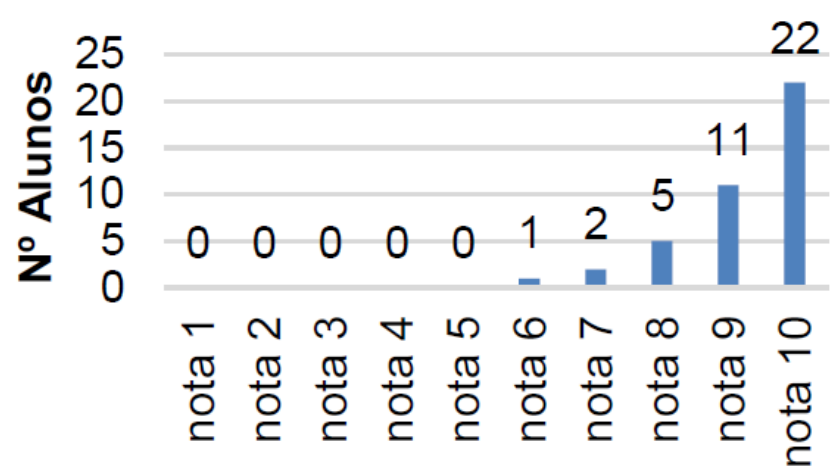

Avaliação

Em relação ao apoio que os pacientes sentiram em relação ao grupo de alunos, a positividade também foi satisfatória, visto que $100 \%$ deles (Gráfico 5) mostraram em algum sentido um acolhimento senão total, parcialmente fazendo um paralelo com a pergunta onde a abordagem foi a aproximação que eles tiveram com os estudantes (gráfico 2). 0 mesmo acontece quando foram perguntados sobre o quanto o paciente estava à vontade com a visita e as perguntas relativas à sua doença (Gráfico 6). 
Gráfico 7. As perguntas sobre a sua doença ajudaram você a falar abertamente (ou melhor) sobre os seus sentimentos?

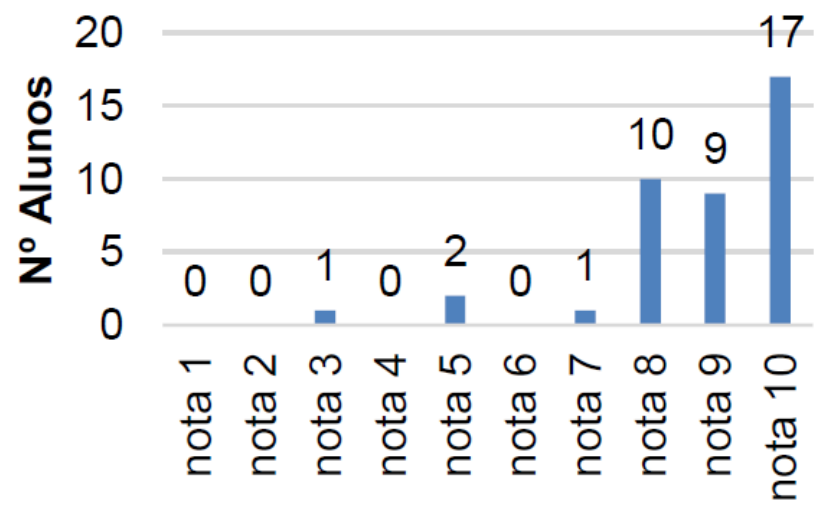

\section{Avaliação}

Gráfico 8. Você sente que os alunos estão preparados para lhe apoiar ou lhe acolher diante dos sentimentos envolvidos na sua doença?

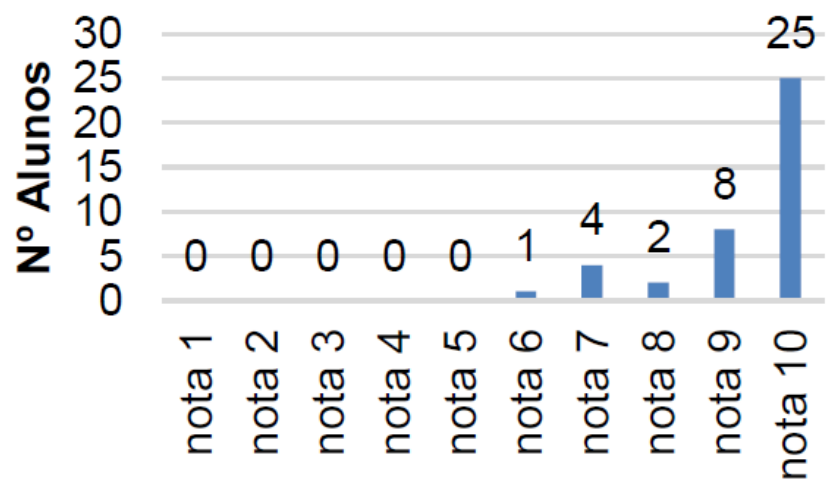

Avaliação

As questões relativas aos sentimentos dos pacientes também foram explanadas e a maioria conseguiu falar abertamente sobre o tema, com exceção de uma pessoa $(2,5 \%$ Gráfico 7) que não ficou à vontade, pois devido ao seu contexto social entende que uma conversa entre médico (aqui representado pelos estudantes de medicina) e paciente deve ser pontual e precisa, sem delongas, numa relação que nos remete a alguns anos atrás onde o médico era visto como o detentor inquestionável do conhecimento.

Já sobre o preparo dos alunos, a pergunta ํㅡo oito (Gráfico 8) demonstra o quanto eles estão preparados para dar uma palavra de conforto, acolher e entender o que se passa com cada indivíduo internado, um ser que deve ser visto como um todo e não fragmentado, 
pois ele não é somente o ser biológico, mas psicossocial e a relação que o paciente tem sobre a doença e os sentimentos que isso envolve traz uma carga de maior responsabilidade para os alunos enquanto formação e médicos enquanto formados.

Gráfico 9. Você acha importante que os alunos de Medicina aprendam esse tipo de entrevista com os pacientes?

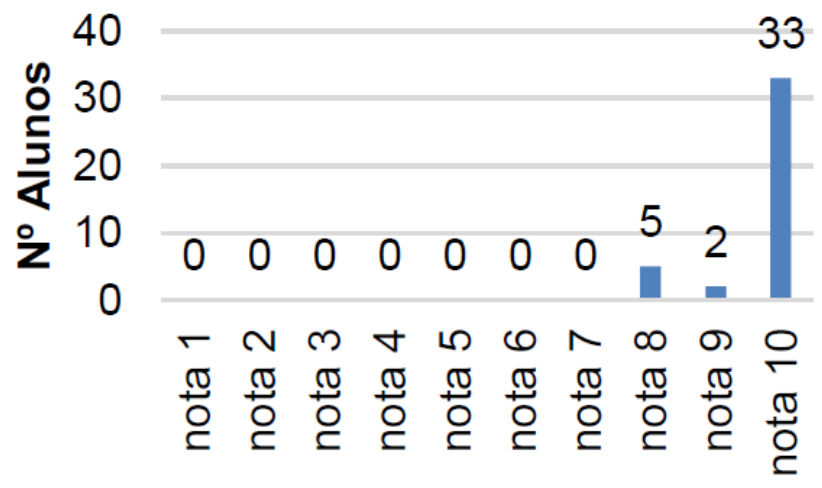

Avaliação

Por fim, a importância que os pacientes dão ao atendimento dos acadêmicos de medicina é de extrema relevância. Todos eles (gráfico 9), em graus variados, expuseram o quão bem faz para ambos os lados, onde o aprendizado é contínuo. Incorporar questões relativas aos seus sentimentos foi algo que os internados não estavam acostumados, mas de forma geral sentiram-se bem e relatavam que isso deixa a relação mais próxima e produtiva.

\section{CONSIDERAÇÕES FINAIS}

A análise e a avaliação do presente estudo permitiram a percepção de que a busca pelo acolhimento e compreensão dos sentimentos envolvidos em cada paciente, após uma conversa com alunos que representaram os grupos Balint, se faz importante em diversos sentidos, pois dentre outros benefícios nos mostra a dimensão do cuidado em uma nova perspectiva, amplia o entendimento dos fatores emocionais envolvidos em suas patologias, busca instrumentos que avaliam a efetividade desses grupos na vida dos pacientes e, sobretudo, concede apoio aos diferentes e singulares momentos de cada um, vividos a fim de atender suas reais necessidades.

Além disso, a incorporação de simples questões na anamnese do cotidiano relacionadas 
aos sentimentos dos pacientes e como tem sido para ele a convivência com o distúrbio ou patologia, revela uma diminuição do "gap" que separa médico/aluno do indivíduo que está à sua frente, seja numa consulta de rotina ou num leito de hospital. O respeito pelo paciente e a forma como o profissional da saúde lida com ele influi diretamente em sua adesão ao tratamento e/ou recuperação.

\section{REFERÊNCIAS}

BALINT, M. O médico, seu paciente, e a doença. 2. ed. Rio de Janeiro: Atheneu; 1988. BACKES, Dirce Stein; LUNARDI FILHO, Wilson Danilo; LUNARDI, Valéria Lerch. Humanização hospitalar: percepção dos pacientes. Acta Sci. Health Sci, v. 27, n. 2, p. 103$107,2005$.

BALDUINO, Paula Martins et al. A perspectiva do paciente no roteiro de anamnese: o Olhar do estudante. Rev. bras. educ. méd, v. 36, n. 3, p. 335-342, 2012.

BERK, Ronald A. The active ingredients in humor: Psychophysiological benefits and risks for older adults. Educational Gerontology, v. 27, n. 3-4, p. 323-339, 2001. PESSINI, L. Humanização do cuidado no ambiente hospitalar. Mundo Saúde, v. 27, n. 2, p. 236-7, 2003.

CALVETTI, Prisla Ücker; MULLER, Marisa Campio; NUNES, Maria Lúcia Tiellet. Psicologia da saúde e psicologia positiva: perspectivas e desafios. Psicologia: ciência e profissão, v. 27, n. 4, p. 706-717, 2007.

CRESWELL, John W.; CLARK, Vicki L. Plano. Pesquisa de Métodos Mistos-: Série Métodos de Pesquisa. 2 ed. Porto Alegre: Penso Editora, 2015.

DANNER, Deborah D.; SNOWDON, David A.; FRIESEN, Wallace V. Positive emotions in early life and longevity: findings from the nun study. Journal of personality and social psychology, v. 80, n. 5, p. 804, 2001.

DAVIS, Mark H. Measuring individual differences in empathy: Evidence for a multidimensional approach. Journal of personality and social psychology, v. 44, n. 1, p. 113126, 1983. 
DE OLIVEIRA, Beatriz Rosana Gonçalves; COLLET, Neusa; VIERA, Cláudia Silveira. A humanização na assistência à saúde. Revista Latino-Americana de Enfermagem, v. 14, n. 2, p. 277-284, 2006.

DE SOUZA MINAYO, María C. O desafio do conhecimento. Pesquisa qualitativa em saúde..10. ed. São Paulo: HUCITEC, 2007. 406 p.

DYNIEVICZ, A. M. Metodologia da pesquisa em saúde para iniciantes. São Caetano do Sul (SP). Difusão, 2007.

GROSSEMAN, Suely; PATRÍCIO, Zuleica Maria. A relação médico-paciente e o cuidado humano: subsídios para promoção da educação médica. Rev. bras. educ. med, v. 28, n. 2, p. 99-105, 2004. HEIDEGGER, Martin. Ser e tempo. vol. I e II, 4. ed. Tradução de Márcia de Sá Cavalcante. Petrópolis: Vozes. 1993.

JEAMMET, P. H.; REYNAUD, Michel; CONSOLI, Silla. Manual de psicologia médica. Rio de Janeiro: MEDSI; 2000.

MACEDO, Paula Costa Mosca; NOGUEIRA-MARTINS, Maria Cezira Fantini; NOGUEIRAMARTINS, Luiz Antonio. Técnicas de intervenção psicológica para humanização nas equipes de saúde: Grupos Balint e Grupos de Reflexão sobre a tarefa assistencial. Knobel E, Andreoli PBA, Erlichman MR, organizadores. Psicologia e humanização: assistência aos pacientes graves. São Paulo: Atheneu, p. 325-341, 2008.

MAHONY, Diana L.; BURROUGHS, W. Jeffrey; LIPPMAN, Louis G. Perceived attributes of health-promoting laughter: A cross-generational comparison. The Journal of Psychology, v. 136, n. 2, p. 171-181, 2002.

MARTIN, Rod A. Humor, laughter, and physical health: methodological issues and research findings. Psychological bulletin, v. 127, n. 4, p. 504, 2001.

MISSENARD, André et al. A experiência Balint: história e atualidade. São Paulo: Casa do Psicólogo, 1994. 
MORAIS, NA de; KOLLER, Sílvia H.; KOLLER, S. H. Abordagem ecológica do desenvolvimento humano, psicologia positiva e resiliência: Ênfase na saúde. Ecologia do desenvolvimento humano: Pesquisa e intervenção no Brasil, p. 91-107, 2004.

SANTOS, Joäo Barberino. Ouvir o paciente: a anamnese no diagnóstico clínico. Brasília méd, v. 36, n. 3/4, p. 90-95, 1999.

SUCUPIRA, Ana Cecília. A importância do ensino da relação médico-paciente e das habilidades de comunicação na formação do profissional de saúde. InterfaceComunicação, Saúde, Educação, v. 11, n. 23,, p.619-35, 2007.

TURATO, Egberto Ribeiro. Tratado da metodologia da pesquisa clínico- qualitativa: construção teórico-epistemológica, discussão comparada e aplicação nas áreas da saúde e humanas.3.ed. Petrópolis: Vozes. 2008.

VIDELA, MirtaMirta Videla. Prevención: Intervención Psicológica en salud comunitaria. Ediciones Cinco, 1998.

ZIMERMAN, David E. A formação psicológica do médico. Mello. Filho J. Psicossomática hoje. Porto Alegre: Artes Médicas, 1992. 